\title{
Aerosolized Liposomal Rubitecan
}

National Cancer Institute

\section{Source}

National Cancer Institute. Aerosolized Liposomal Rubitecan. NCI Thesaurus. Code C61071.

An aerosolized liposomal preparation of rubitecan, a water-insoluble derivative of camptothecin with potential antineoplastic activity. Rubitecan (or 9-nitro-20 (S)camptothecin) and its active metabolite 9-aminocamptothecin (9-AC) selectively stabilize topoisomerase I-DNA covalent complexes during S-phase, thereby inhibiting religation of topoisomerase I-mediated single-strand DNA breaks and producing potentially lethal double-strand DNA breaks when encountered by the DNA replication machinery. This agent is formulated with dilauroylphosphatidylcholine and nebulized in particle sizes of 1.2-1.6 micrometer mass median aerodynamic diameter. 